\title{
A methodology for evaluating land suitability for medicinal plants at a regional level
}

\author{
Marco Barbaro, Alvaro Rocca, Francesco Danuso \\ Department of Agricultural and Environmental Sciences, University of Udine, Italy
}

\begin{abstract}
Before introducing a new crop in an area, such as medicinal plant species, crop-land suitability analysis is a prerequisite to achieve an optimum exploitation of the available land resources for a sustainable agricultural production. To evaluate the land suitability it is important to take into account the habitats of the plant species. Moreover, agronomic, logistic and product quality aspects have to be considered. The importance of these aspects changes according to the stakeholders: the local government is more involved in supporting environmental suitability and production sustainability, farmers need areas which satisfy agronomic and logistic requirements, while industry is interested in the quality of production. A methodology was developed and implemented to create suitability maps for medicinal plants. Because of the generally limited information about medicinal plant adaptation, a simple methodology, based on a priori information has been developed, based on three different criteria: i) environmental suitability (point of view of local government); ii) agronomic, productivity and logistic suitability (point of view of the farmer); iii) quality suitability (point of view of industry). For each of the three criteria, a specific macro-indicator, based on land characteristics, was calculated using membership functions. Here, a methodology to create maps for the introduction of such species was developed and implemented. This methodology can be repeated by command scripts in an easy-to-use
\end{abstract}

Correspondence: Dr. Marco Barbaro, Università di Udine, Dipartimento di Scienze Agrarie ed Ambientali, via delle Scienze 208, 33100 Udine, Italy. Tel. +39.0432.558614 - Fax: +39.0342 .558603 .

E-mail: marco.barbaro@uniud.it

Key words: land suitability, model, evaluation methodology, medicinal plants, Geograpghic Information System.

Acknowledgements: this work was developed in the framework of the project "Filiera per la Propagazione e la Coltivazione della Gentiana lutea L. in Friuli Venezia Giulia" supported by Friuli Venezia Giulia Region (art. 17, L.R. 10/2005 n.26). The authors whish to thank Romano Giovanardi for his guidance in the project and Claudio Liva for his support in the preparation of input data. They also wish to thank the SITFOR (Sistema Informativo territoriale del Friuli Venezia Giulia).

Received for publication: 11 October 2011.

Accepted for publication: 17 September 2011.

(C) Copyright M. Barbaro et al., 2011

Licensee PAGEPress, Italy

Italian Journal of Agronomy 2011; 6:e34

doi:10.4081/ija.2011.e34

This work is licensed under a Creative Commons Attribution NonCommercial 3.0 License (CC BY-NC 3.0). freeware Geograpghic Information System. The structure of the evaluation model can be easily adapted to consider more detailed land information like climate and soil. The methodology (implemented by scripts in a freeware GIS), can be easily repeated and adapted for other situations.

\section{Introduction}

Nowadays, due to a new interest in medicinal plants, there are a lot of scientific studies which could lead to new therapeutic products being developed. For example, research has been carried out on the traditional use and handling of plant species in several Mediterranean countries. These studies form a basis for future phytochemical and pharmacological studies (Gonzales-Tejero et al., 2008).

Medicinal plants are important not only for the pharmaceutical industry, but also for the cosmetics, liqueur and food sectors (Ramawat and Merillon, 2008). However, the cultivation of these plants has become necessary to preserve their wild populations; moreover, in order to be competitive in the international market, it is important to develop an efficient production chain to reduce costs and improve the quality of the products (Marzi and De Mastro, 2008). Before introducing a new crop in a particular area, such as medicinal plants, crop-land suitability analysis is a prerequisite to achieve an optimum exploitation of the available land resources for a sustainable agricultural production (Nisar Ahamed et al., 2000).

Several GIS-based procedures for the evaluation of the crop land suitability have been devised. Sicat Rodrigo et al. (2004) used a fuzzy modeling method to analyze farmers' knowledge to create an agricultural land suitability classification. Liu et al. (2006) showed methods to assess the land suitability of the Qinling Mountains of China, where some suitability scores were compared with the observed land cover to determine whether land should be reallocated to a new use (Liu et al., 2006). Another procedure, providing information to farmers on the selection of the cropping patterns at a regional level was developed by Pirbalouti (2009). Recently, a methodology was developed to evaluate forest plantation land suitability (Dengiz et al., 2010), whereas Hua et al. (2010) developed a GIS-based prediction methodology for the conservation planning of medicinal plant distributions.

To evaluate land suitability, it is important to know the specific habitat of the plant species of interest. Habitat is an area with a combination of resources (like food, cover, water) and environmental conditions (temperature, precipitation, presence or absence of predators and competitors) that promotes occupancy by individuals of a given species (or population) and allows those individuals to survive and reproduce (Morrison et al., 2006). For plants, the habitat suitability models (HSMs) are tools to evaluate the best areas for growing using territorial knowledge (Hirzel et al., 2001). The HSMs are used both to predict the distribution of a spontaneous medicinal species and to identify the best areas for growing medicinal herbs (Guisan and 
Zimmermann, 2000). As many wild populations of medicinal plants are increasingly endangered due to overexploitation and habitat destruction, the GIS-based methodology might be applied for conservation planning and regional management, and for the identification of the best growing areas. Aspects to be considered are environmental conditions, agronomic practices, crop productivity and logistics. The HSMs can be established from $a$ priori information (general adaptation knowledge about the wild population), or from a posteriori information, obtained from experimental or survey data collected on the territory to be studied (Hirzel et al., 2001).

In the present paper, a HSM methodology for the evaluation of the land suitability for cropping medicinal plants has been developed. This methodology has been applied to two medicinal plants: gentian (Gentiana symphyandra Murb.) and lavender (Lavanda spp.). Gentiana symphyandra Murb. is employed both in the liquor industry and for some pharmaceutical preparations (Giovanardi and Barbaro, 2009). Its success in the sector of alcoholic beverages is due to the fact that the root contains some of the most bitter substances found in nature (Barbaro et al., 2008). It grows spontaneously on mountain pasture lands and it is present in different sites of pre-Alps, Alps and Appenines (Aiello and Bezzi, 1998). Also lavender (Lavanda spp.) is of important economic value in the cosmetic and pharmaceutical industries (Corbetta et al., 2001). Because of the limited information available for the study area about gentian and lavender, the developed methodology has been based on a priori information. Such methodology has some specific characteristics: i) it is not plant-specific, so it can be used for different plant species; ii) it can be easily repeated in different areas; iii) it is possible to apply the evaluation procedure for sensitivity analysis and Monte Carlo uncertainty estimation; iv) the repeatability permits a reduction of the implementation costs of the procedure and an easy re-running of the procedure in the case of missing or wrong input data; v) it is possible to check the correctness of the procedure step-bystep and not only on the final maps. The proposed methodology has been implemented with command scripts in an easy-to-use freeware raster GIS (SemGrid).

\section{Materials and Methods}

The development of the procedure to create suitability maps required the following steps: i) the definition of the evaluation model; ii) the preparation of input maps and parameter tables; iii) the implementation of the procedure in a raster GIS framework.

\section{Definition of the evaluation model}

The details of the evaluation model are described below. Because the success of a supply chain of a crop production relies on the satisfaction of different criteria, the territory has been evaluated according to three different point of view:

- environmental suitability: point of view of local government;

- agronomic and logistic suitability: point of view of the farmer;

- quality suitability: point of view of industry.

For each of the three criteria, a specific macro-indicator, based on land characteristics, was defined and calculated using fuzzy membership functions (Nisar et al., 2000; Sicat Rodrigo et al., 2005) (Figure 1).

The macro-indicator for environmental suitability (ISn) was calculated as the mean of an indicator of adaptation to altitude (Ialta) and another one related to the insolation of the site $(I h s)$ :

$$
I S n=(I a l t a+I h s) / 2
$$

The agronomic and logistic suitability macro-indicator (ISr) should represent agronomical aspects like productivity, general adaptation of the species and the management easiness of the crop and its products. It is calculated as the mean of four indicators: 1) the macro-indicator for environmental suitability (Isn), as previously calculated; 2) the productivity of the site, estimated according to altitude (Ialtr); 3 ) the slope (Islope) that can represent a constraint for cropping; 4) the equivalent distance (Idieq) that assesses the reachability of the site on the basis of the difference in height and the distance from each cell to the nearest road. This indicator has been devised in consideration of the energetic costs of walking on the flat and walking on a slope (Schena and Leonardi, 2007).

$$
I S r=(I s n+I \text { Ialtr }+ \text { Islope }+ \text { Idieq }) / 4
$$

The quality suitability macro-indicator (ISq) was calculated as the mean of the productivity indicator (Isn) and the indicator of quality in relationship to altitude (Ialtq):

$$
I S q=(I s n+I a l t q) / 2
$$

The global suitability index $(I S)$ was obtained by a weighted average of all the three macro-indicators, multiplied by a soil suitability index (Iuso) obtained from the land use map. In this map only the cells representing crops, grass and pasture land are selected. These cells received the value of one, while the others were set to zero.

All indicators mentioned, except Iuso, have a continuous value in the range between 0 and 1 ( 1 being the best value, 0 being the worst).

The different indicators have been calculated from the land characteristics, using the membership functions reported in Figure 1.

The function which represents the land suitability index IV is:

$$
I S=I u s o \cdot(P n \cdot I S n+P r \cdot I S r+P q \cdot I S q)
$$

where: $P n+P r+P q=1$

$P n, P r$ and $P q$ are coefficients which give different weight to the indicators. $P n$ is related to the point of view of local government, $P r$ to the point of view of the farmer and $P q$ to the point of view of industry.

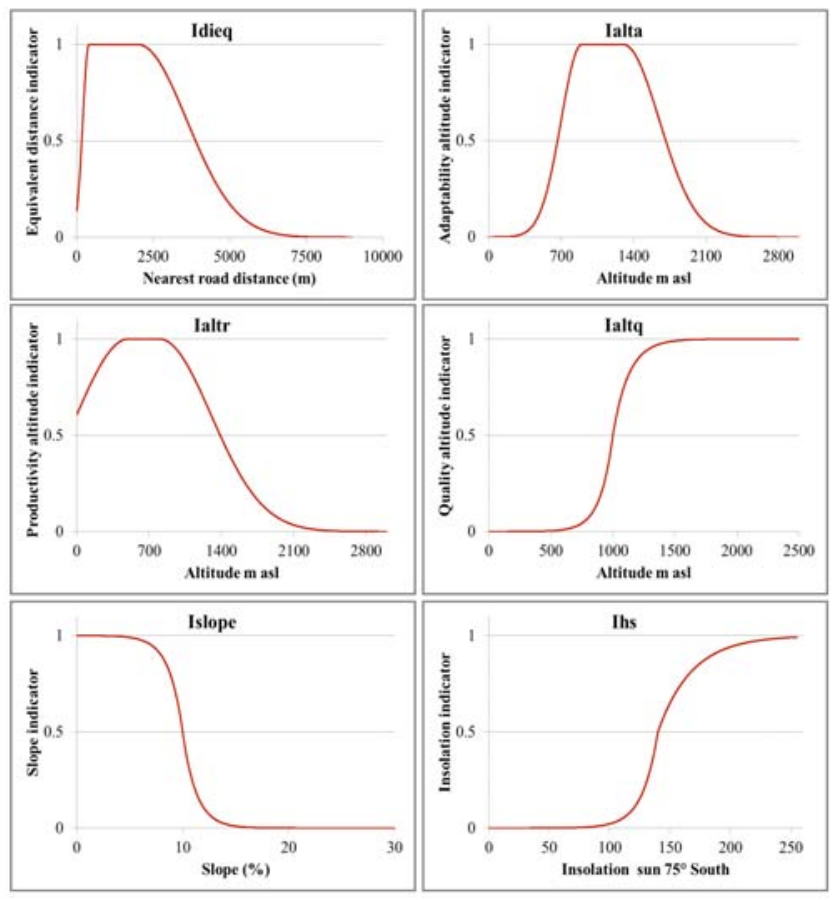

Figure 1. Fuzzy membership functions adopted for the calculation of the indicators. The curves are those for gentian obtained using the specific parameters reported in Table 1 . 
The land suitability map was obtained by classification the suitability index $I V$ into a discrete index with five classes. The procedures for the calculation of the suitability index have been applied to each cell of the raster input maps to obtain the suitability map.

\section{Preparation of the input maps and parameter tables}

The following cartographic data were processed to apply the evaluation procedure: i) digital elevation model (DEM); ii) land use and road network maps; iii) vegetation map. All this information was obtained from the database of the regional forestry system (SITFOR - FVG region). DEM information were altitude (m asl), slope (\%) and insolation (calculated for a sun elevation of $75^{\circ}$, south oriented and also considering the hill shading). Map, minimum distance from roads $(\mathrm{m})$, and the gradient between road and fields (m) were obtained from the road network. From the vegetation map, the cropping potential of suitable land (pastures, arable areas, natural grassland, sparsely vegetated areas and abandoned land) were considered.

\section{Implementation of the procedure in a raster GIS environment}

The model was implemented as a script of commands for the raster GIS SemGrid (Danuso and Sandra, 2006). A script is a list of commands performing different actions like, for example, grid layer importation from other GIS, cell classification, point spatialization, production of maps and map exportation to other GIS. The interaction with the user occurs by both commands or by dialog windows. SemGrid can import and export ASCII grids of different formats. Its main features are: map algebra; statistical evaluation of data (descriptive statistics, regression and neural network models); Markov chain estimation and simulation for spatial data; full support for random number generation; easy interfacing with SEMoLa simulation models; overlay, distance maps, point spatialization; point data table import and export. It implements the Gstat, FragStats and HyGrid2k2 packages. One of the most powerful characteristic of SemGrid is the possibility to easily create scripts which are useful to implement complex land evaluation procedures.

Execution of the land evaluation procedure (Figure 2) requires: the input layers as ASCII grid, a table of parameters for each medicinal plant, a table with the weights for the different macro-indicators, the script with the calculation procedure, and the raster GIS SemGrid. The script for land evaluation is reported in the Appendix.

The user has to prepare its own layers for the study area and can then use the suggested parameters for different plants or create new parameters for other plants, updating the standard parameter table in a spreadsheet format. Moreover, the user has the opportunity to give preferred weights to the macro-indicators, updating the standard weights' table.

\section{Case study}

The study area was the hilly and mountainous areas (424,900 ha) of the Friuli Venezia Giulia region, in north-eastern Italy. This territory was represented by a grid of about $2.66 \mathrm{M}$ cells measuring $40 \mathrm{x}$ $40 \mathrm{~m}$ each. All this information was obtained from the database of the regional forestry system (SITFOR, sistema informativo territoriale del Friuli Venezia Giulia http://www.regione.fvg.it ).

The land suitability map was obtained by classification of the index $I V$ into five discrete classes. To apply the evaluation procedure, the following cartographic data were processed: digital elevation model (DEM); land use and road network maps (JRC, 2000); vegetation map. The areas suitable for gentian and lavender cropping (arable soil, no tilled soil, field, pasture and soil with scarce vegeta-

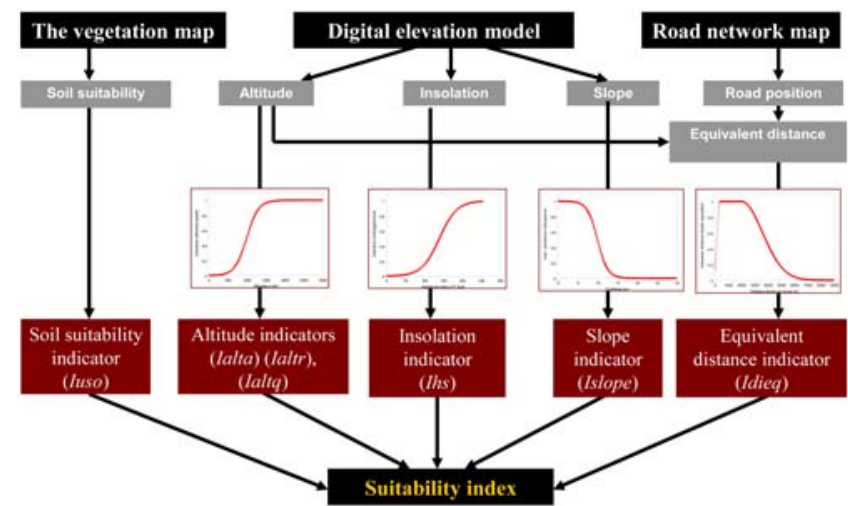

Figure 2. Information flow in the evaluation procedure.

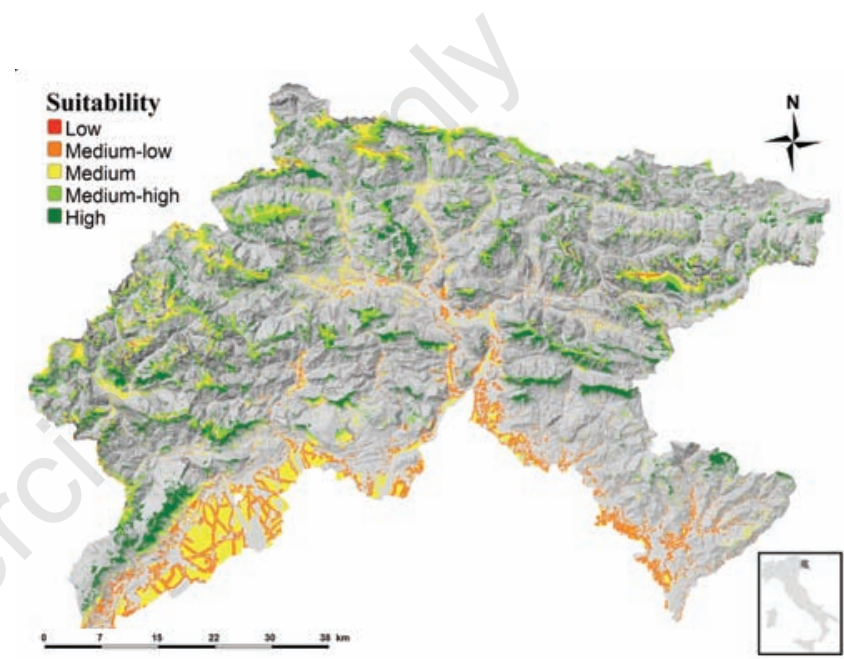

Figure 3. Land suitability maps for gentian in the mountainous and hilly areas of FVG region. In red and in orange the best areas to grow gentian are shown.

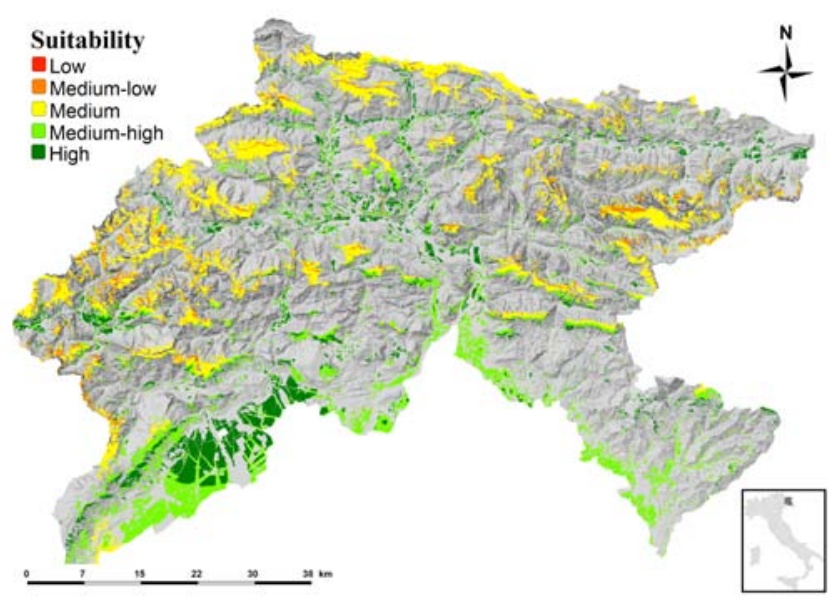

Figure 4. Land suitability maps for lavender in the mountainous and hilly areas of FVG region. The best areas to grow lavender are shown in red and orange. 
tion) were evaluated from the vegetation map (Figures 2 and 3). The calculation procedure was carried out by implementing a script for the raster GIS SemGrid. Land input data and crop parameters were also defined (Table 1).

\section{Results and Discussion}

The evaluation procedure aimed to create a tool to support decision making processes at a regional level, following the principle of the best available information. The implementation of the land evaluation procedure allowed the most suitable areas for cropping gentian and lavender on the considered territory to be identified. Therefore, the results directly depend on the input information, the selected parameters and the calculation procedure. Of course, different parameters and weights will determine different output suitability maps.

In the specific case, it is possible to observe the two suitability maps obtained for gentian and lavender for the Friuli Venezia Giulia region (Figures 3 and 4 ). In the study area, the potential cropping surface for the two species was about 92,000 ha, corresponding to the areas with soil cover classified as pastures, arable areas, natural grassland, sparsely vegetated areas and abandoned land; 8104 ha of these have been classified with high suitability for gentian and 20935 ha for lavender. An analysis of the maps shows that, as expected, the areas with highest suitability index (IV) for lavender and for gentian are strictly associated with exposition, altitude and distance from roads. In particular, it can be seen that the most suitable areas for lavender are the lowland; this is, in contrast, the most unsuitable area for gentian.

The evaluation model does not include other aspects such as socioeconomic conditions or competition with other crops that could be considered in the assessment of mountain areas.

\section{Conclusions}

This paper reports the creation of a methodology to evaluate crop suitability of medicinal plants. This methodology, based on land information, can be a useful tool to create suitability maps considering environmental adaptation, productivity, quality of the production and logistics requirements. With the aim of developing productive chains for the cultivation of medicinal plants, this method can provide information for local governments to generate optimum land-use plans at a regional level. For example, subsidies for the cultivation of medicinal herbs should only be given for areas suitable for cultivation.

The proposed methodology can be easily adapted to different medicinal plants. For the application of the procedure, a spreadsheet dataset (with specific parameters for each plant) and grid layers with land characteristics are required as inputs. The methodology can be applied without the knowledge of complex programming languages and, because of its general approach, it can be used for any territory. Of course, the availability of more information will allow parameter values to be better defined and will provide an empirical validation of the model. The evaluation model will also be improved by incorporating spatialized information about climate and soil.

However, the structure of the evaluation model can be easily adapted to consider more detailed land information, such as climate and soil.

Table 1. Parameters of the evaluation procedure. The values suggested for Gentiana lutea and Lavanda ssp. are reported. The names of parameters are those used in the membership functions of the procedure script (see Appendix).

\begin{tabular}{|c|c|c|c|c|c|}
\hline Parameter & Description & Gentiana lutea & Lavanda spp. & Used in indicator & \\
\hline PaltAdOptl & Min best altitude for adaptation of the crop & $\mathrm{m}$ & 900 & 300 & Ialta \\
\hline PaltAdOpt2 & Max best altitude for adaptation of the crop & $\mathrm{m}$ & 1300 & 800 & Ialta \\
\hline PaltAdSD1 & Altitude for adaptation (standard deviation 1) & $\mathrm{m}$ & 200 & 200 & Ialta \\
\hline PaltAdSD2 & Altitude for adaptation (standard deviation 2) & $\mathrm{m}$ & 350 & 300 & Ialta \\
\hline PaltReOptl & Min altitude for optimal productivity & $\mathrm{m}$ & 500 & 100 & Ialtr \\
\hline PaltReOpt2 & Max altitude for optimal productivity & $\mathrm{m}$ & 800 & 500 & Ialtr \\
\hline PaltReSD1 & Altitude for productivity (standard deviation 1) & $\mathrm{m}$ & 500 & 500 & Ialtr \\
\hline PaltReSD2 & Altitude for productivity (standard deviation 2) & $\mathrm{m}$ & 500 & 500 & Ialtr \\
\hline PaltQuMax & Medium altitude for quality & $\mathrm{m}$ & 1000 & 100 & Ialtq \\
\hline PaltQuMin & Minimum altitude for quality & $\mathrm{m}$ & 600 & 300 & Ialtq \\
\hline PaltQuFr & Maximum altitude for quality & $0-1$ & 1500 & 900 & Ialtq \\
\hline PpendMax & Max completely suitable slope & $\%$ & 5 & 5 & Islope \\
\hline PpendMaxAct & Slope acceptable & $\%$ & 8 & 8 & Islope \\
\hline PpendNoAc & Slope limit for cropping & $\%$ & 15 & 15 & Islope \\
\hline PinsoMin & Minimum insolation & $0-255$ & 20 & 20 & Ihs \\
\hline PinsoMed & Medium insolation & $0-255$ & 150 & 150 & Ihs \\
\hline PinsoMax & Maximum insolation & $0-255$ & 250 & 250 & Ihs \\
\hline PDiEql & Best equivalent distance 1 & $\mathrm{~m}$ & 400 & 400 & Idieq \\
\hline PDiEq2 & Best equivalent distance 2 & $\mathrm{~m}$ & 2000 & 2000 & Idieq \\
\hline PdiEqSD1 & Equivalent distance (standard deviation 1) & $\mathrm{m}$ & 200 & 200 & Idieq \\
\hline PdiEqSD2 & Equivalent distance (standard deviation 2) & $\mathrm{m}$ & 1600 & 1600 & Idieq \\
\hline
\end{tabular}




\section{References}

Aiello N., Bezzi A., 1998. Genziana maggiore (Gentiana lutea L.): aspetti biologici, qualitativi e produttivi. Agricoltura Ricerca 176:8-17.

Barbaro M., Putignano E., Cividino S.R., Giovanardi R., 2008. Evaluation of native populations of gentian (Gentiana lutea ssp. Symphyandra) of the Friulan Pre-Alps. Ital. J. Agron. 3(Suppl.3):429-430.

Corbetta F., De Santis A., Forlani L., Murari G., 2001. Piante Officinali Italiane - Il Nuovo Lodi. Edagricole, Bologna, Italy.

Danuso F., Sandra M., 2006. SemGrid: land application of epidemiological and crop models. Proc. 9th ESA Congr. Bibliotheca Fragmenta Agronomica 2:631-632.

Dengiz 0., Gol C., Sargioglu F.E., Edis S., 2010. Parametric approach to land evaluation for forest plantation: a methodological study using GIS model. Afr. J. Agric. Res. 5:1482-1496.

Giovanardi R., Barbaro M., 2009. Sviluppo della Filiera produttiva della Genziana Maggiore in Friuli Venezia Giulia. Forum Ed., Verona, Italy.

Gonzales-Tejero M.R., Casares-Porcel M., Sanchez-Rojas C.P., RamiroGutierrez J.M., Molero-Mesa J., Pieroni A., Giusti M.E., Censorii E., de Pasquale C., Della A., Paraskeva-Hadijchambi D., Hadjichambis A., Houmani Z., El-Demerdash M., el-Zayat M., Hmamouchi M., ElJorhrig S., 2008. Medicinal plants in the Mediterranean area: synthesis of the results of the project Rubia. J. Ethnopharmacol. 116:341-357.

Guisan A., Zimmermann N. E., 2000. Predictive habitat distribution models in ecology. Ecol. Model. 135:147-186

Hirzel A.H., Helfer V., Metral F., 2001. Assessing habitat-suitability mod- els with a virtual species. Ecol. Model.145:111-121.

Hua Y., Caixiang X., Jingyuan S., Yingqun Z., Shilin C., 2010. TCMGISII based prediction of medicinal plant distribution for conservation planning: a case study of Rheum tanguticum. Chinese Medicine $5: 31$.

Liu Y.S., Wang J.Y., Guo L.Y., 2006. GIS-based assessment of land suitability for optimal allocation in the qinling mountains, China. Pedosphere 16:579-586.

JRC Joint Research Centre-Institute for Environment and Sustainability, 2002. Final report of "Moland project in Friuli Venezia Giulia region". Available from: http://www.dpvta.uniud.it/ Danuso/docs/SemGrid/SemGid.htm and http://www.regione.fvg.it

Marzi V., De Mastro G., 2008. Piante Officinali. Mario Adda Ed., Bari, Italy.

Morrison M.R., Marcot B.R., Mannan R.W., 2006. Wildlife-Habitat Relationship. Concept and Application. University of Wisconsin Press, Madison, WI, USA.

Nisar A.T.R., Gopal R.K., Murthy J.S.R., 2000. GIS-based fuzzy membership model for crop-land suitability. Agric. Syst. 63:75-95.

Pirbalouti A.G., 2009. GIS-based land suitability evaluation for rapeseed oil crop. J. Food Agric. Environ. 7:837-840.

Ramawat K.G., Merillon J.M., 2008. Bioactive Molecules and Medicinal Plants. Springer-Verlag Berlin, Germany.

Schena F., Leonardi A., 2007. Prescription of exercise for mountain physical and sport activities. Proc. 2nd Mountain, Sport and Health Int. Congr., Rovereto, TN, Italy.

Sicat Rodrigo S., Carranza E.J.M., Nidumolu U.B., 2005. Fuzzy modeling of farmers knowledge for land suitability classif. Agric. Syst. 83:4975. 